Jolume 20, Nomor 2, Mei 2021, pp 107-118. Copyright (C) 2021 Jurnal
Manajemen Maranatha, Program Studi S-1 Manajemen, Fakultas Ekonomi,
Universitas Kristen Maranatha. ISSN 1411-9293 | e-ISSN 2579-4094.
https://journal.maranatha.edu/index.php/jmm

\title{
Perceived ease of use, trust, dan customer satisfaction sebagai prediktor terhadap repurchase intention
}

\author{
Yanico Yanico \\ Fakultas Ekonomi dan Bisnis Universitas Tarumanagara, Jl. Tanjung Duren Utara No. 1 Grogol, \\ Jakarta Barat, 11410, Indonesia \\ yanico.115170384@stu.untar.ac.id \\ Keni Keni* \\ Fakultas Ekonomi dan Bisnis Universitas Tarumanagara, Jl. Tanjung Duren Utara No. 1 Grogol, \\ Jakarta Barat, 11410, Indonesia \\ keni@fe.untar.ac.id \\ *Penulis Korespondensi
}

Submitted: Jan 02, 2021; Reviewed: Jan 13, 2021; Accepted: May 04, 2021

\begin{abstract}
This study aimed to determine wheteher or not the perceived ease of use, trust, and customer satisfaction can predict repurchase intention at the e-commerce industry in Jakarta. This study applies online questionnaires that are distributed electronically for data collection. In data collection, 195 respondents participed in filling out the questionnaire, and 176 data could be processed in data processing. Data processing in this study used the PLS-SEM approach, which is using the help of SMART PLS software. Based on the results of data analysis in this study, researchers concluded that the perceived ease of use, trust, and customer satisfaction are significant in predicting repurchases intentions. The results of this research are expected to be information for e-commerce companies to establish strategies related to the use of applications in improving the ease of use of e-commerce applications in the form of ease of product search and ease of payment processing and delivery. In addition, the results of the research are expected that e-commerce companies can provide reliable services and reliable and guaranteed security systems to increase customer trust. Furthermore, ecommerce companies can develop various marketing programs to improve customer satisfaction.
\end{abstract}

Keywords: customer satisfaction; perceived ease of use; repurchase intention; trust Abstrak: Penelitian ini bertujuan untuk mengetahui apakah perceived ease of use, trust, dan customer
satisfaction dapat memrediksi repurchase intention pada industri e-commerce di Jakarta. Penelitian
ini mengaplikasikan penggunaan kuesioner online yang dibagikan secara elektronik untuk
pengumpulan data. Dalam pengumpulan data sebanyak 195 orang responden yang berpartisipasi
dalam pengisian kuesioner, dan sebanyak 176 data yang dapat diproses dalam pengolahan data.
Pengolahan data pada penelitian ini menggunakan pendekatan PLS-SEM, yang mana menggunakan
bantuan dari perangkat lunak berupa SMART PLS. Berdasarkan hasil dari analisis data pada
penelitian ini, peneliti menyimpulkan bahwa kemudahan pemakaian yang dirasakan, kepercayaan,
dan kepuasan dari pelanggan signifikan dalam memrediksi niat pembelian ulang. Hasil-hasil
penelitian ini diharapkan menjadi informasi bagi perusahaan e-commerce untuk menetapkan strategi
terkait penggunaan aplikasi dalam meningkatkan kemudahan penggunaan aplikasi e-commerce
berupa kemudahan dalam pencarian produk serta kemudahan dalam proses pembayaran dan
pengiriman. Di samping itu, hasil-hasil penelitian diharapkan bahwa perusahaan e-commerce dapat
DoI: https://doi.org/10.28932/jmm.v20i2.3244 
memberikan pelayanan terpercaya serta sistem keamanan yang terpercaya dan terjamin untuk meningkatkan kepercayaan pelanggan. Lebih lanjut, perusahaan e-commerce dapat mengembangkan berbagai program pemasaran untuk meningkatkan kepuasan pelanggan.

Kata kunci: customer satisfaction; perceived ease of use; repurchase intention; trust

\section{PENDAHULUAN}

Transformasi sistem perdagangan dimulai dari sistem barter, kemudian berlanjut ke pasar tradisional, selanjutnya ke pasar modern atau biasanya disebut pasar swalayan, dan berlanjut ke sistem perdagangan pasar digital di mana pasar digital mengharuskan pelaku usaha untuk mengikuti perkembangan teknologi. Perkembangan teknologi saat ini diikuti dengan berkembangnya internet yang membantu memfasilitasi sistem perdagangan digital yang saat ini kita sebut dengan pasar online. Pada era digital, terdapat banyak keuntungan bagi pelaku usaha dalam mendirikan industri $e$ commerce untuk menawarkan produk kepada para pembeli, juga memberikan tantangan kepada pelaku usaha untuk tetap bertahan serta berkembang dan maju dalam menjalankan usahanya. Hal ini dipantau dari segi bagaimana sebuah perusahaan untuk mengikuti perkembangan dan pembaharuan bisnisnya dalam menawarkan kebutuhan pelanggan. E-commerce sebagai salah satu bidang usaha penggerak perekonomian perlu untuk kompetitif dalam menjalankan usahanya. Agar dapat kompetitif dalam menjalankan usahanya, industri e-commerce perlu untuk mendapatkan retensi dari pelanggan. Sebuah bisnis perdagangan barang maupun jasa dapat berjalan dengan baik apabila dapat menarik niat pembelian ulang dari para pelanggannya. Repurchase intention atau niat pembelian ulang mengacu pada probabilitas subjektif bahwa seorang individu akan terus membeli produk dari vendor atau toko online di masa depan (Fang et al., 2011). Dalam menjalankan sebuah bisnis, pembelian ulang sangat dibutuhkan dan menjadi kunci keberhasilan sebuah usaha, dalam hal ini perusahaan e-commerce, di mana agar sebuah usaha dapat berkembang dan maju, perusahaan perlu meningkatkan daya pembelian dan pembelian ulang dari konsumen maupun pelanggan.

Salah satu faktor yang memengaruhi repurchase intention adalah perceived ease of use. Menurut Keni (2020), perceived ease of use positif dan signifikan dalam memrediksi repurchase intention. Hasil penelitian ini bertolak belakang dengan Mohamed et al. (2014) yang menunjukkan hasil penelitian bahwa perceived ease of use tidak signifikan dalam memengaruhi repurchase intention. Selanjutnya, menurut Trivedi \& Yadav (2018), trust dapat memrediksi repurchase intention secara positif dan signifikan, sedangkan beberapa hasil penelitian terdahulu yang menyatakan bahwa trust tidak signifikan dalam memrediksi repurchase intention (Kassim \& Abdullah, 2010; Wen et al., 2011). Lebih lanjut, Chiu \& Cho (2019) menjelaskan bahwa customer satisfcation positif dan signifikan dalam memrediksi repurchase intention.

Berdasarkan uraian di atas, diketahui bahwa terdapat perbedaan hasil penelitian dari penelitian terdahulu. Adapun tujuan dari penelitian ini adalah untuk mengetahui apakah perceived ease of use, trust, dan customer satisfaction dapat memrediksi repurchase intention pada industri e-commerce di Jakarta. Dengan melakukan penelitian ini, diharapkan dapat memberikan kontribusi positif bahwa repurchase intention pada industri e-commercce dapat diprediksi oleh perceived ease of use, trust, dan customer satisfaction, sehingga dapat mengisi kesenjangan penelitian sebelumnya. Kontribusi penelitian kepada perusahaan adalah diharapkan perusahaan dapat meningkatkan kemudahan dalam menggunakan aplikasi e-commerce, kemudahan dalam pembayaran, serta pengiriman dapat ditingkatkan oleh perusahaan guna untuk meningkatkan tingkat niat pembelian ulang. Selanjutnya, perusahaan e-commerce dapat meningkatkan kepercayaan dengan cara membangun hubungan yang baik dengan pelanggan untuk meningkatkan niat pembelian ulang. Lebih lanjut, perusahaan $e$ commerce dapat meningkatkan program untuk memuaskan pelanggannya, seperti membangun inovasi baru dalam memberikan pelayanan dan mendesain website agar dapat menarik, sehingga dapat menarik niat pembelian ulang dari pelanggan.

Salah satu variabel yang dapat menjelaskan repurchase intention adalah perceived ease of use. Dalam konteks belanja online, perceived ease of use mengacu pada sejauh mana konsumen percaya bahwa belanja online akan bebas dari usaha (Chiu et al., 2009). Pada penelitian terdahulu oleh Lee et 
al. (2011) ditemukan bahwa persepsi mudah digunakan positif memengaruhi atau mempunyai pengaruh terhadap pembelian ulang. Pengalaman seseorang terhadap penggunaan belanja online yang mudah terhadap platform belanja online tersebut akan memberikan perspektif positif pada pengguna tersebut untuk melakukan pembelian ulang terhadap toko belanja online tersebut. Lebih lanjut, penelitian yang dilakukan oleh Keni (2020) menjelaskan bahwa perceived ease of use berpengaruh positif terhadap repurchase intention pada penelitian terhadap sektor e-commerce di Indonesia. Berdasarkan uraian peneliti terdahulu di atas, hipotesis penelitian dapat dirumuskan sebagai berikut: H1: Perceived ease of use secara positif memrediksi repurchase intention pada industri e-commece di Jakarta.

Variabel berikutnya yang dapat menjelaskan repurchase intention adalah trust. Trust, menurut Cron \& Decarlo (2010), mengacu pada sebuah pendapat bahwa kata janji dari seseorang dapat diyakini dan bahwa kepentingan jangka panjang pelanggan dapat dilayani. Dalam penelitian terdahulu oleh Trivedi \& Yadav (2018) ditemukan bahwa kepercayaan memiliki hubungan positif terhadap pembelian ulang. Ketika seseorang dalam melakukan transaksi dan mendapatkan hasil yang menyenangkan akan membawa rasa kepercayaan terhadap sebuah toko fisik maupun online, dan pada akhirnya akan membawa orang tersebut dalam melakukan pembelian ulang. Selanjutnya, pada penelitiannya oleh Wilson \& Keni (2018) menemukan bahwa trust secara langsung memiliki hubungan positif terhadap repurchase intention, penelitian tersebut menjelaskan bahwa pelanggan yang telah percaya akan melakukan pembelian ulang di kemudian hari pada perusahaan yang sama. Lebih lanjut, Chiu et al. (2009) menemukan bahwa trust pada penjual online berpengaruh pada repurchase intention. Dalam hal ini, semakin sebuah kepercayaan atas sebuah toko online tumbuh dalam diri konsumen maupun pelanggan tersebut, maka semakin besar peluang akan melakukan pembelian ulang pada masa mendatang. Berdasarkan uraian peneliti terdahulu di atas, hipotesis penelitian dapat dirumuskan sebagai berikut:

H2: Trust secara positif memrediksi repurchase intention pada industri e-commerce di Jakarta.

Variabel selanjutnya yang dapat menjelaskan repurchase intention adalah customer satisfaction. Customer satisfaction, menurut Kotler \& Keller (2016), merupakan perasaan seseorang akan senang atau kecewa yang dirasakan dari perbandingan kinerja produk yang dirasakan (atau hasil) dalam kaitannya dengan harapannya. Pada penelitian terdahulu oleh Keni (2020), ditemukan bahwa customer satisfaction berpengaruh positif terhadap repurchase intetnion pada penelitian terhadap sector $e$ commerce di Indonesia. Lebih lanjut, penelitian terhadulu oleh Wilson et al. (2019) menemukan bahwa customer satisfaction memiliki pengaruh positif terhadap repurchase intention. Penelitian lainnya oleh Chen (2012) menemukan bahwa customer satisfaction memiliki hubungan positif terhadap repurchase intention, dinyatakan bahwa satisfaction merupakan faktor yang memengaruhi repurchase intention dari para pelanggan. Berdasarkan uraian peneliti terdahulu di atas, hipotesis penelitian dapat dirumuskan sebagai berikut:

H3: Customer satisfaction secara positif memrediksi repurchase intention pada industri e-commerce di Jakarta.

\section{METODE}

Desain penelitian dalam penelitian ini adalah desain penelitian descriptive. Menurut Malhotra (2020), desain penelitian descriptive bertujuan untuk menjelaskan fungsi dan karakteristik dari sebuah pasar. Penelitian ini menggunakan desain penelitian descriptive karena penelitian ini menjelaskan dan mendeskripsikan sifat dan karakteristik dari sebuah peristiwa. Dalam desain penelitian descriptive, terdapat cross-sectional designs dan longitudinal designs. Penelitian ini menggunakan cross-sectional designs, yang mana cross-sectional designs melibatkan pengambilan informasi dari sampel tertentu dari elemen populasi hanya sekali (Malhotra, 2020). Populasi dalam penelitian ini merupakan seluruh pelanggan industri e-commerce. Dalam penelitian ini, peneliti menggunakan teknik pengambilan sampel berupa convenience sampling dengan cara menyebarkan sampel secara elektronik, yang mana pengambilan sampel melibatkan elemen-elemen yang nyaman menurut peneliti (Malhotra, 2020). Teknik convenience sampling memungkinkan peneliti dapat efektif dan efisien dalam pengambilan sampel. Ukuran sampel dalam penelitian ini sebanyak 176 sampel yang telah valid untuk dikelola 
lebih lanjut. Angka tersebut telah memenuhi syarat sampel sebuah penelitian yang berkisar dari 30 sampai dengan 500 sampel (Roscoe, 1975; dalam Bougie \& Sekaran, 2020). Pengambilan sampel dalam penelitian ini dilakukan dengan menyebarkan kuesioner dari google form yang disebarkan secara online atau secara elektronik melalui media sosial (facebook, instagram, line, dan whatsapp) kepada para responden. Penelitian ini menggunakan empat variabel yaitu, repurchase intention, perceived ease of use, trust, dan customer satisfaction.

Tabel 1. Operasional variabel dan indikator penelitian

\begin{tabular}{|c|c|c|c|}
\hline Variabel & Indikator & Kode & Sumber \\
\hline $\begin{array}{l}\text { Repurchase } \\
\text { intention }\end{array}$ & $\begin{array}{l}\text { Jika saya bisa, saya ingin terus menggunakan situs web } \\
\text { untuk membeli produk. } \\
\text { Kemungkinan saya akan terus membeli produk dari } \\
\text { situs web pada masa depan. } \\
\text { Saya akan teratur berbelanja online di situs web di } \\
\text { masa depan. }\end{array}$ & RI04 & $\begin{array}{l}\text { Chiu \& Cho } \\
\text { (2019), Mohamed } \\
\text { et al. (2014), Chen } \\
(2012)\end{array}$ \\
\hline $\begin{array}{l}\text { Perceived } \\
\text { ease of use }\end{array}$ & $\begin{array}{l}\text { Saya akan mencari kemudahan penggunaan pasar } \\
\text { online. } \\
\text { Mudah untuk menjadi terampil dalam menggunakan } \\
\text { situs web. } \\
\text { Berbelanja di website mudah dimengerti. } \\
\text { Berbelanja online tidak memerlukan upaya mental } \\
\text { yang banyak. } \\
\text { Mudah untuk belajar menggunakan internet untuk } \\
\text { belanja. }\end{array}$ & $\begin{array}{l}\text { PE01 } \\
\text { PE02 } \\
\text { PE03 } \\
\text { PE04 } \\
\text { PE05 }\end{array}$ & $\begin{array}{l}\text { Trevedi \& Yadav } \\
\text { (2018), Chiu et al. } \\
\text { (2009), Lee et al. } \\
\text { (2011), Chen } \\
\text { (2012) }\end{array}$ \\
\hline Trust & $\begin{array}{l}\text { Berdasarkan pengalaman, toko online peduli dengan } \\
\text { pelanggan. } \\
\text { Berdasarkan pengalaman, toko online jujur. } \\
\text { Situs web menawarkan keamanan data pribadi yang } \\
\text { dapat dipercaya. } \\
\text { Berdasarkan pengalaman, toko online menepati janji. } \\
\text { Sekuritas transaksi meningkatkan kepercayaan. }\end{array}$ & $\begin{array}{l}\text { T01 } \\
\text { T02 } \\
\text { T03 } \\
\text { T04 } \\
\text { T05 }\end{array}$ & $\begin{array}{l}\text { Chiu et al. (2009), } \\
\text { Lee et al. (2011) }\end{array}$ \\
\hline $\begin{array}{l}\text { Customer } \\
\text { satisfaction }\end{array}$ & $\begin{array}{l}\text { Puas dengan pengalaman dalam berbelanja online. } \\
\text { Keputusan yang bijak untuk berbelanja online. } \\
\text { Senang dengan pengalaman berbelanja online. } \\
\text { Berbelanja online merupakan ide bagus. }\end{array}$ & $\begin{array}{l}\text { CS01 } \\
\text { CSO2 } \\
\text { CS03 } \\
\text { CS04 }\end{array}$ & $\begin{array}{l}\text { Mohamed et al. } \\
(2014), \text { Fang et al. } \\
(2011), \text { Chen } \\
(2012)\end{array}$ \\
\hline
\end{tabular}

Sumber: Diolah dari berbagai sumber

Pernyataan kuesioner disusun berdasarkan indikator dari setiap variabel dalam penelitian ini. Dengan menggunakan skala pengukuran berupa skala Likert dengan poin 1-5, yang mana poin 1 (sangat tidak setuju), 2 (tidak setuju), 3 (netral), 4 (setuju), dan 5 (sangat setuju). Dengan hasil pengumpulan sampel total 176 sampel yang valid, dapat diolah lebih lanjut menggunakan analisis structural equation modelling dengan pendekatan PLS-SEM. PLS-SEM merupakan pendekatan kausal dari structural equal modelling yang bertujuan untuk memaksimalkan variansi yang dijelaskan dari konstruk laten dari variabel dependen (Hair et al., 2011). Dalam SEM, penelitian ini menggunakan bantuan software SMARTPLS untuk mengolah data.

Dalam analisis data menggunakan SEM, terdapat dua model pendekatan untuk pengujian, yaitu pengujian outer model dan pengujian inner model. Outer model bertujuan untuk menjelaskan tentang measurement dalam penelitian tersebut dan inner model bertujuan untuk mengetahui hubungan antara konstruk atau variabel yang diamati dalam sebuah penelitian (Hair et al., 2014).

\section{HASIL DAN PEMBAHASAN}

\subsection{Hasil outer model}

Menurut Malhotra (2020), untuk mencapai convergent validity, nilai dari average variance extracted (AVE) dari setiap variabel yang diamati harus lebih tinggi dari 0,5. Hasil pengolahan pada Tabel 2 menunjukkan setiap variabel memeroleh nilai di atas ketentuan 0,5 , sehingga dapat dinyatakan valid. 
Tabel 2. Hasil convergent validity (average variance extracted)

\begin{tabular}{ccc}
\hline Variabel & $\begin{array}{c}\text { Average variance } \\
\text { extracted }\end{array}$ & Status \\
\hline $\begin{array}{c}\text { Customer } \\
\text { satisfaction }\end{array}$ & 0,704 & Valid \\
$\begin{array}{c}\text { Perceived ease of } \\
\text { use }\end{array}$ & 0,643 & Valid \\
$\begin{array}{c}\text { Repurchase } \\
\text { intention } \\
\text { Trust }\end{array}$ & 0,821 & Valid \\
\hline
\end{tabular}

Sumber: Hasil pengolahan SMARTPLS

Menurut Hair et al. (2014), untuk mencapai convergent validity, nilai dari setiap item pada outer loading harus lebih besar atau di atas 0,7. Hasil dari pengolahan data pada Tabel 3 menunjukkan bahwa nilai outer loading telah memenuhi kriteria yaitu di atas 0,7 .

Tabel 3. Hasil convergent validity (outer loading)

\begin{tabular}{ccccc}
\hline & $\begin{array}{c}\text { Customer } \\
\text { satisfaction }\end{array}$ & $\begin{array}{c}\text { Perceived ease } \\
\text { of use }\end{array}$ & $\begin{array}{c}\text { Repurchase } \\
\text { intention }\end{array}$ & Trust \\
\hline CS01 & 0,790 & & & \\
CS02 & 0,871 & & & \\
CS03 & 0,863 & & & \\
CS04 & 0,829 & & & \\
PE01 & & 0,728 & & \\
PE02 & & 0,876 & & \\
PE03 & & 0,850 & & \\
PE04 & & 0,754 & & \\
PE05 & 0,774 & 0,886 & 0,752 \\
R102 & & 0,924 & 0,822 \\
R103 & & 0,908 & 0,779 \\
R104 & & & & 0,727 \\
T01 & & & \\
T02 & & & \\
T03 & & & & \\
T04 & & & & \\
T05 & & & & \\
\hline
\end{tabular}

Sumber: Hasil pengolahan SMARTPLS

Hasil pengolahan data menunjukkan validitas diskriminan dalam penelitian ini, hal ini dikarenakan berdasarkan hasil Tabel 4 menunjukkan nilai dari validitas diskriminan yang mana nilai korelasi variabel yang diamati lebih baik daripada menjelaskan variabel lainnya. Nilai korelasi tersebut merupakan akar kuadrat dari nilai AVE variabel yang diamati.

Tabel 4. Hasil discriminant validity (fornell-larker creation)

\begin{tabular}{ccccc}
\hline & $\begin{array}{c}\text { Customer } \\
\text { satisfaction }\end{array}$ & $\begin{array}{c}\text { Perceived } \\
\text { ease of use }\end{array}$ & $\begin{array}{c}\text { Repurchase } \\
\text { intention }\end{array}$ & Trust \\
\hline $\begin{array}{c}\text { Customer satisfaction } \\
\text { Perceived ease of use }\end{array}$ & 0,839 & & & \\
Repurchase intention & 0,712 & 0,802 & & \\
Trust & 0,714 & 0,599 & 0,906 & \\
\hline
\end{tabular}

Sumber: Hasil pengolahan SMARTPLS

Tabel 5 menunjukkan hasil cross loading pada penelitian ini. Menurut Henseler et al. (2009), untuk memenuhi validitas diskriminan dari konstruk yang diamati dapat diketahui dari nilai cross loading pada indikator dari konstruk yang diamati harus lebih besar atau tinggi dari nilai cross loading pada indikator dari konstruk lainnya. Dari hasil tersebut, menunjukkan bahwa nilai dari setiap indikator pada variabel yang diamati lebih tinggi dibandingkan pada indikator variabel lainnya. Oleh karena itu, validitas diskriminan pada variabel yang diamati dalam penelitian ini sudah terpenuhi. 
Jurnal Manajemen Maranatha ø Vol. 20 Nomor 2, Mei (2021)

Tabel 5. Hasil discriminant validity (cross loading)

\begin{tabular}{ccccc}
\hline & $\begin{array}{c}\text { Customer } \\
\text { satisfaction }\end{array}$ & $\begin{array}{c}\text { Perceived ease } \\
\text { of use }\end{array}$ & $\begin{array}{c}\text { Repurchase } \\
\text { intention }\end{array}$ & Trust \\
\hline CS01 & $\mathbf{0 , 7 9 0}$ & 0,644 & 0,518 & 0,607 \\
CS02 & $\mathbf{0 , 8 7 1}$ & 0,606 & 0,569 & 0,667 \\
CS03 & $\mathbf{0 , 8 6 3}$ & 0,563 & 0,469 & 0,597 \\
CS04 & $\mathbf{0 , 8 2 9}$ & 0,569 & 0,535 & 0,526 \\
PE01 & 0,573 & $\mathbf{0 , 7 4 8}$ & 0,479 & 0,508 \\
PE02 & 0,583 & $\mathbf{0 , 8 7 6}$ & 0,533 & 0,613 \\
PE03 & 0,549 & $\mathbf{0 , 8 5 0}$ & 0,469 & 0,561 \\
PE04 & 0,584 & $\mathbf{0 , 7 5 4}$ & 0,513 & 0,562 \\
PE05 & 0,560 & $\mathbf{0 , 7 7 4}$ & 0,383 & 0,509 \\
RI02 & 0,552 & 0,522 & $\mathbf{0 , 8 8 6}$ & 0,512 \\
RI03 & 0,582 & 0,544 & $\mathbf{0 , 9 2 4}$ & 0,588 \\
RI04 & 0,569 & 0,562 & $\mathbf{0 , 9 0 8}$ & 0,591 \\
T01 & 0,511 & 0,503 & 0,484 & $\mathbf{0 , 7 5 2}$ \\
T02 & 0,624 & 0,591 & 0,516 & $\mathbf{0 , 8 2 2}$ \\
T03 & 0,513 & 0,529 & 0,503 & $\mathbf{0 , 7 7 9}$ \\
T04 & 0,579 & 0,559 & 0,537 & $\mathbf{0 , 8 4 4}$ \\
T05 & 0,601 & 0,534 & 0,389 & $\mathbf{0 , 7 2 7}$ \\
\hline Sun
\end{tabular}

Sumber: Hasil pengolahan SMARTPLS

Tabel 6 menunjukkan hasil dari uji reliabilitas. Penelitian ini menggunakan nilai dari cronbach's alpha dan composite reliability sebagai pengukur reliabilitas terhadap variabel yang diamati. Masing-masing nilai pengukur tersebut harus lebih besar dari 0,6 dan 0,7, sehingga menunjukkan reliabilitas (Malhotra, 2020). Hasil Tabel 6 menunjukkan bahwa setiap variabel memiliki nilai cronbach's alpha dan composite reliability yang memenuhi ketentuan, oleh sebab itu setiap variabel memenuhi syarat reliabilitas.

Tabel 6. Hasil uji reliabilitas

\begin{tabular}{cccc}
\hline Variabel & $\begin{array}{c}\text { Cronbach's } \\
\text { alpha }\end{array}$ & $\begin{array}{c}\text { Composite } \\
\text { reliability }\end{array}$ & Status \\
\hline $\begin{array}{c}\text { Customer } \\
\text { satisfaction }\end{array}$ & 0,859 & 0,905 & Reliabel \\
$\begin{array}{c}\text { Perceived ease of } \\
\text { use }\end{array}$ & 0,860 & 0,900 & Reliabel \\
$\begin{array}{c}\text { Repurchase } \\
\text { intention } \\
\text { Trust }\end{array}$ & 0,891 & 0,932 & Reliabel \\
\hline
\end{tabular}

Sumber: Hasil pengolahan SMARTPLS

Gambar 1 berikut menunjukkan hasil pengolahan PLS algorithm, yang menjelaskan arah penelitian. 


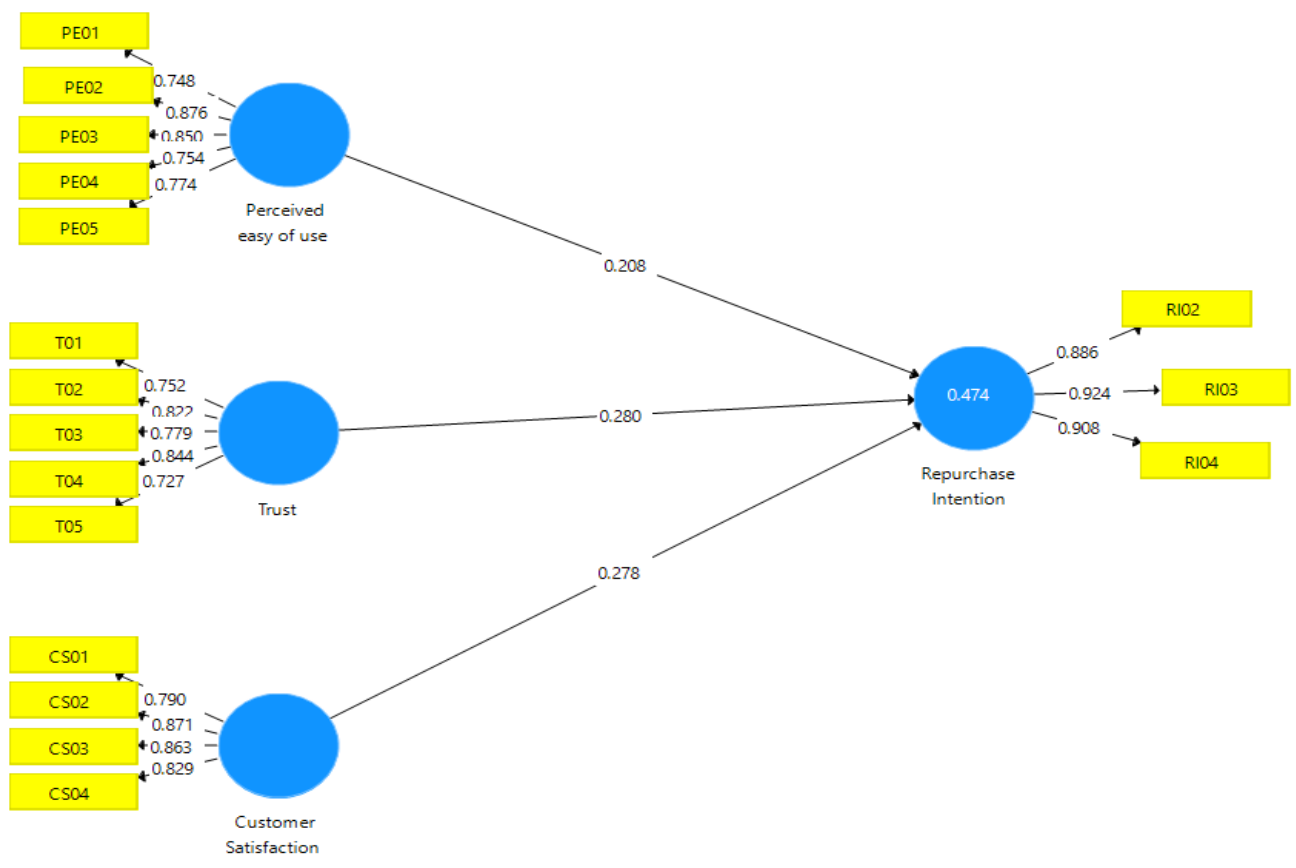

Gambar 1. Hasil pengolahan PLS algorithm

Sumber: Hasil pengolahan SMARTPLS

\subsection{Hasil inner model}

Pengujian inner model terdiri dari pengujian coefficient of determination $\left(\mathrm{R}^{2}\right)$, cross-validited redundancy $\left(\mathrm{Q}^{2}\right)$, path coefficient, effect size $\left(f^{2}\right)$, uji GoF, dan hasil uji hipotesis. Berdasarkan hasil analisis R-square terhadap model penelitian yang didapatkan dari analisis data, diperoleh bahwa nilai $\mathrm{R}$-square sebesar 0,474 atau sebesar 47,4\%. Dapat diartikan bahwa variabel perceived ease of use, trust, dan customer satisfaction dalam penelitian ini memberikan pengaruh sebesar 47,4\% terhadap repurchase intention; sedangkan 52,6\% sisanya dipengaruhi oleh variabel lainnya, misalnya perceived usefulness, privacy concern, security, dan variabel lainnya. Tabel 7 menunjukkan hasil $\mathrm{R}^{2}$.

Tabel 7. Hasil coefficient of determination $\left(\mathrm{R}^{2}\right)$

\begin{tabular}{cc}
\hline Variabel & $\mathrm{R}^{2}$ \\
\hline Repurchase intention & 0,474 \\
\hline
\end{tabular}

Sumber: Hasil pengolahan SMARTPLS

Selanjutnya, melalui pengujian terhadap cross-validited redundancy $\left(\mathrm{Q}^{2}\right)$, didapatkan nilai $\mathrm{Q}^{2}$ dari variabel repurchase intention sebesar 0,369. Sebuah model penelitian harus memiliki predictive relevance atau nilai $\mathrm{Q}^{2}$ yang lebih besar dari 0 . Oleh karena itu, hasil analisis tersebut menunjukkan bahwa model penelitian dalam penelitian ini memiliki predictive relevance. Tabel 8 menunjukkan hasil cross-validited redundancy.

Tabel 8. Hasil cross-validited redundancy $\left(\mathrm{Q}^{2}\right)$

\begin{tabular}{cc}
\hline Variabel & $\mathrm{Q}^{2}$ \\
\hline Repurchase intention & 0,369 \\
\hline
\end{tabular}

Sumber: Hasil pengolahan SMARTPLS

Pengujian inner model lain pada penelitian ini adalah path coefficient. Hasil dari path- coefficient dari jalur variabel perceived ease of use ke repurchase intention memberikan kontribusi nilai pathcoefficient sebesar 0,208. Selanjutnya, jalur variabel trust ke repurchase intention memberikan kontribusi nilai path-coefficient sebesar 0,280. Lebih lanjut, jalur variabel customer satisfaction ke 
repurchase intention memberikan kontribusi nilai path coefficient sebesar 0,278. Ketiga jalur variabel tersebut memberikan efek positif. Efek positif dari jalur penelitian tersebut memberikan arti bahwa ketiga variabel memiliki pengaruh searah terhadap repurchase intention. Selain itu, dapat diambil kesimpulan bahwa dari ketiga variabel tersebut, yang memberikan kontribusi terbesar ialah variabel trust. Tabel 9 menunjukkan hasil path coefficient.

Tabel 9. Hasil path coefficient

\begin{tabular}{ccc}
\hline Path analysis & $\begin{array}{c}\text { Nilai path } \\
\text { coefficient }\end{array}$ & Status \\
\hline Perceived ease of use $\rightarrow$ Repurchase intention & 0,208 & Positif \\
Trust $\rightarrow$ Repurchase intention & 0,280 & Positif \\
Customer satisfaction $\rightarrow$ Repurchase intention & 0,278 & Positif \\
\hline
\end{tabular}

Sumber: Hasil pengolahan SMARTPLS

Selanjutnya, pengujian inner model juga menggunakan analisis effect of size. Berdasarkan hasil analisis effect of size pada penelitian ini, variabel perceived ease of use, trust, dan customer satisfaction dalam menjelaskan variabel repurchase intention yang memiliki keterwakilan kecil. Hal ini dikarenakan nilai $f^{2}$ dari effect of size $\left(f^{2}\right)$ berupa 0,02 menunjukkan bahwa keterwakilan variabel independen kecil dalam menjelaskan variabel dependen, nilai effect of size $\left(f^{2}\right)$ berupa 0,15 menunjukkan bahwa keterwakilan variabel independen medium dalam menjelaskan variabel dependen, dan nilai effect of size $\left(f^{2}\right)$ berupa 0,35 menunjukkan bahwa keterwakilan sebuah variabel independen kuat dalam menjelaskan variabel dependen (Hair et al., 2014). Tabel 10 menunjukkan hasil $f^{2}$.

Tabel 10. Hasil effect of size

\begin{tabular}{cc}
\hline Variabel & $\boldsymbol{f}^{2}$ \\
\hline Perceived ease of use $\rightarrow$ Repurchase intention & 0,035 \\
Trust $\rightarrow$ Repurchase intention & 0,063 \\
Customer satisfaction $\rightarrow$ Repurchase intention & 0,058 \\
\hline
\end{tabular}

Sumber: Hasil pengolahan SMARTPLS

Pengujian inner model juga melibatkan uji goodness of fit. Menurut Wetzels et al. (2009), goodness of fit dari sebuah model dikategorikan dalam tiga ketentuan kinerja sebuah model, yaitu berupa nilai GoF $F_{\text {small }}$ sebesar 0,1, GoF $F_{\text {medium }}$ sebesar 0,25, dan $G o F_{\text {large }}$ sebesar 0,36. GoF $F_{\text {small }}$ mengartikan bahwa sebuah model menunjukkan kinerja kecil pada PLS, GoF medium mengartikan bahwa sebuah model menunjukkan kinerja medium pada PLS, dan $G o F_{\text {large }}$ mengartikan bahwa sebuah model menunjukkan kinerja besar pada PLS. Hasil pengujian menunjukkan perhitungan GoF sebagai berikut:

$$
\text { GoF }=\sqrt{\overline{A V E} \times \overline{R^{2}}}
$$

Rata-rata AVE $=(0,704+0,643+0,821+0,618): 4=\mathbf{0 , 6 9 6 5}$

Rata-rata $\mathrm{R}$ square $=\mathbf{0 , 4 7 4}$

maka:

$$
\begin{aligned}
& G o F=\sqrt{0,6965 \times 0,474} \\
& G o F=\mathbf{0 , 5 7 4 5 7}
\end{aligned}
$$

Dapat disimpulkan bahwa nilai dari $G o F$ adalah sebesar 0,5746, artinya bahwa kinerja dari model penelitian ini menghasilkan $G o F_{\text {large }}$, yang mana 0,5746 lebih tinggi dari 0,36 $\left(G o F_{\text {large }}\right)$. Oleh sebab itu, model penelitian ini menunjukkan performa baik sesuai dengan tingkat ketentuan pada goodness of fit.

Lebih lanjut, untuk pengujian inner model, diperlukan pengujian terhadap hipotesis penelitian. Tabel 11 menunjukkan hasil pengujian hipotesis dengan menggunakan ketentuan nilai dari $p$-value dan t-value. Agar sebuah hipotesis didukung, ketentuan terhadap nilai $p$-value harus lebih kecil dari 0,05. Lebih lanjut, agar sebuah hipotesis didukung, ketentuan terhadap nilai t-value harus lebih besar 
dari 1,96. Dengan ketentuan tersebut, maka akan diketahui apakah sebuah hipotesis didukung atau tidak didukung. Berdasarkan hasil pengujian, semua hipotesis telah mencapai ketentuan yang ditetapkan. Oleh sebab itu semua hipotesis didukung.

Tabel 11. Hasil uji hipotesis

\begin{tabular}{ccccc}
\hline Hipotesis & Pernyataan hipotesis & P-value & T-value & Status \\
\hline H1 & $\begin{array}{c}\text { Perceived ease of use secara positif memrediksi } \\
\text { repurchase intention pada industri } \text {-commerce } \\
\text { di Jakarta }\end{array}$ & 0,041 & 2,053 & Didukung \\
H2 & $\begin{array}{c}\text { Trust secara positif memrediksi repurchase } \\
\text { intention pada industri } \text { e-commerce di Jakarta }\end{array}$ & 0,048 & 1,986 & Didukung \\
H3 & $\begin{array}{c}\text { Customer satisfaction secara positif memrediksi } \\
\text { repurchase intention pada industri } \text {-commerce } \\
\text { di Jakarta }\end{array}$ & 0,017 & 2,388 & Didukung \\
\hline
\end{tabular}

Sumber: Hasil pengolahan SMARTPLS

\subsection{Pembahasan}

Pada uji hipotesis pertama, yang dilakukan dalam penelitian ini, menyatakan bahwa perceived ease of use secara positif memrediksi repurchase intention pada industri e-commerce di Jakarta. Pada uji hipotesis pertama menghasilkan nilai $p$-value dan nilai t-value yang memenuhi ketentuan dan kriteria yang ditetapkan, maka menghasilkan hipotesis pertama didukung. Dari hasil pengujian hipotesispun sejalan dengan hasil penelitian terdahulu pada penelitian yang dilakukan oleh Chiu et al. (2009); Lee et al. (2011); dan Keni (2020). Pada penelitian oleh Chiu et al. (2009) dan Lee et al. (2011) menemukan bahwa perceived ease of use mempunyai hubungan positif terhadap repurchase intention. Dalam hal ini, mengartikan bahwa kemudahan dalam melakukan pembelian yang dirasakan oleh para pelanggan pada perusahaan $e$-commerce akan memungkinkan pelanggan untuk melakukan pembelian berkelanjutan atau pembelian berulang pada perusahaan e-comnerce yang sama. Selanjutnya, pada penelitiannya, Keni (2020) juga menjelaskan bahwa perceived ease of use berpengaruh positif terhadap repurchase intention. Dalam hal ini, mengartikan bahwa kemudahan yang diberikan sebuah perusahaan (mudah untuk dipelajari dan dipahami, efisien dalam bertransaksi, serta kemudahan dalam melakukan pembayaran ataupun kemudahan dalam proses pengiriman) kepada para pelanggan, akan memungkinkan pelanggan untuk melakukan pembelian ulang terhadap perusahaan yang sama. Hal ini juga berlaku pada sebuah industri e-commerce, yang mana jika terdapat kemudahan dalam pemakaian e-commerce, maka besar kemungkinan pelanggan akan melakukan pembelian ulang industri $e$ commerce tersebut. Perusahaan e-commerce, ke depannya, dalam menjalankan bisnis perlu untuk menawarkan kemudahan pencaharian produk, kemudahan dalam berkomunikasi dengan pihak penjual, kemudahan dalam melakukan pembayaran, dan kemudahan dalam proses pengiriman untuk meningkatkan perceived ease of use dari pelanggan, sehingga tingkat repurchase intention dari perusahaan $e$-commerce dapat meningkat.

Sementara hasi uji hipotesis kedua dalam penelitian ini menjelaskan bahwa trust secara positif memrediksi repurchase intention pada industri e-commerce di Jakarta. Pada proses pengujian hipotesis, menghasilkan nilai $p$-value dan nilai t-value yang memenuhi kriteria dan ketentuan untuk signifikansi hipotesis. Oleh sebab itu, menghasilkan hipotesis kedua didukung dan dapat disimpulkan bahwa trust positif memrediksi repurchase intention. Hasil pengujianpun sejalan dengan penelitian terdahulu yang dilakukan oleh Trivedi \& Yadav (2018); Wilson \& Keni (2018); dan Chiu et al. (2009). Pada penelitian oleh Trivedi \& Yadav (2018), menemukan bahwa trust memliki hubungan positif terhadap repurchase intention. Dapat diartikan bahwa ketika pelanggan memiliki kepercayaan yang kuat terhadap sebuah perusahaan e-commerce, maka akan mudah untuk melakukan pembelian ulang terhadap e-commerce tersebut. Selanjutnya, penelitian oleh Wilson \& Keni (2018) juga menemukan bahwa trust memiliki hubungan positif terhadap repurchase intention. Hal ini dapat diartikan bahwa pelanggan yang telah percaya kepada sebuah perusahaan, besar kemungkinan akan melakukan pembelian ulang pada perusahaan yang sama. Hal ini juga dapat berlaku pada pelanggan sebuah industri e-commerce. Lebih lanjut, pada penelitian yang dilakukan oleh Chiu et al. (2009) menemukan bahwa trust memiliki hubungan positif terhadap repurchase intention. Semakin kepercayaan atas sebuah perusahaan tumbuh pada konsumen maupun pelanggan, maka semakin besar peluang atau 
kemungkinan akan melakukan pembelian ulang pada perusahaan yang sama pada masa mendatang. Oleh sebab itu, perusahaan e-commerce perlu untuk membangun kepercayaan yang kuat dengan pelanggannya. Kepercayaan tersebut dapat dibangun dengan memerkuat hubungan akrab dengan pelanggan serta menawarkan sistem keamanan yang terjamin agar dapat menjaga keamanan para pelanggan dalam aktivitas transaksi, sehingga tingkat kepercayaan pelanggan tinggi dan tingkat untuk melakukan pembelian ulang juga tinggi.

Terakhir, hipotesis ketiga dalam penelitian ini menjelaskan bahwa customer satisfaction secara positif memrediksi repurchase intention pada industri e-commerce di Jakarta. Hasil uji hipotesis menunjukkan bahwa hipotesis ketiga didukung. Dengan nilai $p$-value dan t-value memenuhi kriteria dan ketentuan yang diberlakukan, sehingga menghasilkan signifikansi dalam pengujian hipotesis ketiga dalam penelitian ini. Hasil pengujian hipotesispun sejalan dengan hasil dari penelitian sebelumnya yang menunjukkan signifikansi dari variabel customer satisfaction dalam memrediksi repurchase intention. Pada penelitian sebelumnya oleh Keni (2020) pada sektor e-commerce di Indonesia, menemukan bahwa customer satisfaction memiliki hubungan positif terhadap repurchase intention. Tingkat kepuasan dari pelanggan akan menentukan apakah pelanggan akan melakukan pembelian ulang atau tidak, jika tingkat kepuasan terhadap sebuah perusahaan e-commerce tinggi, maka kemungkinan akan melakukan pembelian ulang besar, begitupun sebaliknya. Selanjutnya, pada penelitian oleh Wilson et al. (2019) terhadap industri e-commerce, menemukan bahwa customer satisfaction memiliki hubungan positif terhadap repurchase intention. Kepuasan pelanggan memainkan peran penting dalam memahami niat pembelian ulang konsumen atau pelanggan. Hal ini juga berlaku pada sebuah industri e-commerce dalam menawarkan kepuasan pelanggan pada saat bertransaksi. Lebih lanjut, pada penelitian oleh Chen (2012) menemukan bahwa customer satisfaction memiliki hubungan positif terhadap repurchase intention. Customer satisfaction merupakan faktor penting yang memengaruhi repurchase intention. Dengan demikian, perusahaan e-commerce perlu untuk menawarkan kepuasaan jangka panjang dengan pelanggannya, dengan cara menawarkan berbagai program pemasaran dalam kegiatan perdagangan, seperti menawarkan bebas biaya pengiriman barang, pemotongan harga, dan lainnya. Lebih lanjut, perusahaan juga perlu untuk membangun kepedulian terhadap pelanggan, sehingga tingkat untuk melakukan pembelian ulang dapat meningkat.

\section{SIMPULAN DAN SARAN}

Dengan diterimanya hipotesis dalam penelitian, maka dapat menjawab rumusan masalah pada penelitian ini. Oleh sebab itu, kesimpulan yang dapat diambil dari hasil pengujian adalah perceived ease of use secara positif memrediksi repurchase intention pada industri e-commerce di Jakarta, trust secara positif memrediksi repurchase intention pada industri e-commerce di Jakarta, dan customer satisfaction secara positif memrediksi repurchase intention pada industri e-commerce di Jakarta.

Keterbatasan dalam penelitian ini berupa variabel yang digunakan dalam meneliti repurchase intention hanya sebatas pada perceived ease of use, trust, dan customer satisfaction. Masih terdapat banyak variabel lain yang dapat diteliti yang berkaitan dengan repurchase intention. Selanjutnya, penelitian ini hanya berfokus pada mengevaluasi repurchase intention. Penelitian ini hanya menggunakan 176 sampel yang dikarenakan terdapat keterbatasan waktu dalam pengambilan sampel dan melakukan penelitian.

Beberapa saran yang peneliti ajukan atas keterbatasan dalam penelitian ini untuk penelitian berkelanjutan, yaitu disarankan peneliti mendatang melakukan penelitian terhadap repurchase intention dapat menggunakan variabel lain, seperti privacy concern dan security (Trivedi \& Yadav 2018) ataupun perceived usefulness (Chiu et al., 2009). Penelitian mendatang juga dapat mencari lagi variabel lain yang dapat memengaruhi repurchase intention. Lebih lanjut, peneliti juga menyarankan kepada penelitian mendatang untuk menggunakan sampel yang lebih banyak dibanding dengan penelitian saat ini.

Saran kepada perusahaan e-commerce terkait hasil penelitian ini adalah dalam meningkatkan kemudahan penggunaan yang dirasakan pelanggan, peneliti menyarankan perusahaan e-commerce harus meningkatkan kemudahan dalam penggunaan aplikasi untuk berbelanja, baik itu kemudahan dalam mencari produk yang diinginkan, kemudahan untuk berkomunikasi dengan pihak penjual, serta 
kemudahan dalam pembayaran maupun kemudahan dalam masalah pengiriman. Dalam meningkatkan kepercayaan dari pelanggannya, peneliti menyarankan perusahaan e-commerce untuk meningkatkan sistem keamanan terjamin dalam melakukan transaksi. Sistem keamanan tersebut dapat berkaitan dengan keamanan data pribadi pelanggan maupun keamanan dalam melakukan pembayaran. Lebih lanjut, untuk meningkatkan kepercayaan, peneliti juga menyarankan perusahaan e-commerce untuk meningkatkan kepedulian dan kejujuran dalam melayani para pelanggannya. Dalam meningkatkan kepuasan pelanggan, peneliti menyarankan agar perusahaan e-commerce dapat mengembangkan program pemasaran berkelanjutan. Program pemasaran yang dimaksud dapat berupa pemberian promosi, pemotongan biaya pengiriman, dan lainnya. Lebih lanjut, untuk meningkatkan kepuasan pelanggan, peneliti juga menyarankan perusahaan e-commerce harus peduli dalam memberikan pelayanannya.

\section{ACKNOWLEDGEMENTS}

Ucapan terima kasih dari peneliti kepada Ketua Lembaga Penelitian dan Pengabdian kepada Masyarakat (LPPM) Universitas Tarumangara yang telah mendanai hibah penelitian tugas akhir ini. Selain itu, ucapan terima kasih peneliti kepada Dekan Fakultas Ekonomi dan Bisnis Universitas Tarumanagara, Ketua Jurusan Manajemen Universitas Tarumanagara, Ketua Program Studi Sarjana Manajemen Universitas Tarumanagara, Tim Editorial Jurnal Komunikasi, serta seluruh pihak yang telah mendukung, membantu, dan berpartisipasi dalam penyelesaian penelitian ini.

\section{REFERENSI}

Bougie, R., \& Sekaran, U. (2020). Research methods for business: A skill building approach. 8th edition. John Willey \& Sons Ltd

Chen, Y. Y. (2012). Why do customers go internet shopping again? Understanding the antecedents of repurchase intention. Journal of Organizational Computing and Electronic Commerce, 22(1), 38-63. https://doi.org/10.1080/10919392.2012.642234

Chiu, C. M., Chang, C. C., Cheng, H. L., \& Fang, Y. H. (2009). Determinants of customer repurchase intention in online shopping. Online Information Review, 33(4), 761-784. https://doi.org/10.1108/14684520910985710

Chiu, W., \& Cho, H. (2019). E-commerce brand: The effect of perceived brand leadership on consumers' satisfaction and repurchase intention on e-commerce websites. Asia Pacific Journal of Marketing and Logistics. https://doi.org/10.1108/APJML-10-2018-0403

Cron, W. L., \& Decarlo, T. (2010). Sales management: Concepts and cases, 10th edition. Wiley India Pvt. Limited

Fang, Y. -H., Chiu, Y. -H., \& Wang, E. (2011). Understanding customers' satisfaction and repurchase intentions: An integration of IS success model, trust, and justice. Internet Research, 21(4), 479503. https://doi.org/10.1108/10662241111158335

Hair, J., Ringle, C., \& Sarstedt, M. (2011). Pls-sem: Indeed a silver bullet. Journal of Marketing Theory and Practice, 19(2), 139-151. https://doi.org/10.2753/MTP1069-6679190202

Hair, J., Sarstedt, M., Hopkins, L., \& Kuppelwieser, V. (2014). Partial least squares structural equation modeling (PLS-SEM): An emerging tool in business research. European Business Review, 26(2), 106-121. https://doi.org/10.1108/EBR-10-2013-0128

Henseler, J., Ringle, C., \& Sinkovics, R.R (2009). The use of partial least square path modeling in international marketing Sinkovics, R.R and Ghauri, P.N. (Ed.) New Challenges to International Marketing (Advances in International Marketing, Vol.20). Emerald Group Publishing Limited, Bingley, pp. 277-319. https://doi.org/10.1108/S1474-7979(2009)0000020014

Kassim, N., \& Abdullah, N. A. (2010). The effect of perceived service quality dimensions on customer satisfaction, trust, and loyalty in e-commerce settings: A cross cultural analysis. Asia Pacific Journal of Marketing and Logistics, 22(3), 351-371. https://doi.org/10.1108/13555851011062269 
Keni, K. (2020). How perceived usefulness and perceived ease of use affecting intent to repurchase. Jurnal Manajemen, 24(3), 481-496. http://dx.doi.org/10.24912/jm.v24i3.680

Kotler, P., \& Keller, K. L. (2016). Marketing management 15 edition. Pearson

Lee, C. H., Eze, U. C., \& Ndubisi, N. O. (2011). Analyzing key determinants of online repurchase intentions. Asia Pacific Journal of Marketing and Logistics, 23(2), 200-221. https://doi.org/10.1108/13555851111120498

Malhotra, N. K. (2020). Marketing research: An applied orientation. Seventh edition. Pearson Education Ltd

Mohamed, N., Hussein, R., Zamzuri, N. A., \& Haghshenas, H. (2014). Insights into individual's online shopping continuance intention. Industrial Management \& Data Systems, 114(9), 14531476. https://doi.org/10.1108/IMDS-07-2014-0201

Trivedi, S. K., \& Yadav, M. (2018). Predicting online repurchase intentions with esatisfaction as mediator: a study on Gen Y. Vine Journal of Information and Knowledge Management Systems, 48(3), 427-447. https://doi.org/10.1108/VJIKMS-10-2017-0066

Wen, C., Prybutok, V., \& Xu, C. (2011). An integrated model for customer online repurchase intention. Journal of Computer Information Systems, 52(1), 14-23. https://thekeep.eiu.edu/business_fac/8

Wetzels, M., Odekerten-Schroder, G., \& Oppen, C. V. (2009). Using PLS path modeling for assesing hierarchical construct models: Guidelines and emperical illustration. MIS Quarterly, 33(1), 177-195. https://www.jstor.org/stable/20650284

Wilson, N., \& Keni, K. (2018). Pengaruh website design quality dan kualitas jasa terhadap repurchase intention: Variabel trust sebagai variabel mediasi. Jurnal Manajemen dan Pemasaran Jasa, 11(2), 291-310. http://dx.doi.org/10.25105/jmpj.v11i2.3006

Wilson, N., Keni, K., \& Tan, P. H. (2019). The effect of website design quality and service quality on repurchase intention in the e-commerce industry: A cross-continental analysis. Gadjah Mada International Journal of Business, 21(02), 187-222. https://doi.org/10.22146/gamaijb.33665 